prepared by the working party of the Association of Anaesthetists, which suggest concentrating resources for treatment of the most seriously ill patients in hospitals that can support more than 200 admissions each year in their intensive therapy units. ${ }^{2}$ This will inevitably mean seriously ill patients being transferred to regional units and is logical in that it concentrates expensive resources and facilitates and localises centres of expertise. I am, however, concerned that patients should not be denied access to such units because of their APACHE score or duration of illness.

N R WEBSTER

St James's University Hospital,

Leeds LS9 7TF

1 Purdie JAM, Ridley SA, Wallace PGM. Effective use of regiona intensive therapy units. Br Med $f$ 1990;300:79-81. (13 intensive

2 Association of Anaesthetists of Great Britain and Ireland. Provision of intensive care. London: Association of Anaesthetists of Great Britain and Ireland, 1988.

SIR, - In their paper on effective use of regional intensive therapy units Dr Jane A M Purdie and colleagues promote the APACHE scoring system as a means to compare outcomes of intensive therapy.' The APACHE system was developed from retrospective analysis of data on patients during the first 24 hours after their admission to an intensive therapy unit. ${ }^{2}$ Attempts to use the system for continuing assessment of care may be erroneous.

For example, doctors in an intensive therapy unit might reasonably decide that earlier, more aggressive management of life threatening diseases would improve survival. If this approach was partially successful an increase in the incidence of low APACHE scores and a fall in overall mortality would be accompanied by a rise in mortality among patients with low scores because success was only partial. The significance of this shift to the left in incidence of APACHE scores is difficult to assess, and a change in overall mortality is an insensitive measure of performance in intensive therapy units. Comparison with other units might well be adverse.

Conversely, if doctors in an intensive therapy unit delayed treatment, allowing APACHE scores to rise, any increase in overall mortality might be compensated by the higher APACHE scores. It is conceivable that mortality would rise only partially and then results comprising high scores in patients would seem superior.

Attempts are now being made to use the APACHE system to audit intensive care. The current Intensive Care Society five year trial should surely not be cited in support of this until its results are published.

G P BECK

Telford Hospital,

Telford

Shropshire TF6 6TF

1 Purdie JAM, Ridley SA, Wallace PGM. Effective use of regional intensive care units. Br Med f 1990;300:79-81. (13 January.)

Knaus WA, Draper EA, Wagner DP, Zimmerman JE. APACHE

II: a severity of disease classification system. Crit Care Med 1985;13:818-29.

Authors' REPLY,-As Dr N R Webster points out, the symbols in the legend of the scatter diagram in our article were inadvertently transposed, and a correction has been published ( 3 February, p 306)

We evaluated only certain factors that might influence the effectiveness of regional intensive care units and did not attempt to compare regional with district care services. It is clear from the text and from the legend of the diagram that 112 patients were analysed, but as 12 patients are superimposed there are only 100 points on the scatter diagram. If $\mathrm{Dr}$ Webster had noted this discrepancy it might have saved him considerable time in reanalysing incomplete data. Our complete data were analysed in this centre by a professional statistician and the analysis accompanied the manuscript of our paper to the $B M F$ for corroboration.

In the group of patients that caused us most concern (those with an APACHE score above 10 whose illness lasted longer than 10 days), of 14 patients transferred, only five survived. Selection is desirable to prevent admission of patients who will not recover to intensive care units, where they may suffer a prolonged and undignified death. Prediction of outcome, however, remains extremely difficult. We agree with both Dr Webster and Dr G $P$ Beck that the APACHE scoring system is an imperfect tool and must be employed with great caution in individual patients. It has, however, been proved internationally to be useful in comparing cohorts of patients.

We do not suggest that admission to an intensive care unit should be denied to any patient on limited evidence, but in high risk groups admission policy should be rigorously "questioned." Identification of two important factors to be considered with all ther aspects of the patient both human and medical may improve overall care.

Western Infirmary Glasgow (ill 6NT

\section{Accounting for consultants}

SIR, - John Warden does us less than justice in his reference to the report on the management and utilisation of operating theatres.' The report runs to 90 pages with factual appendices twice this length. It took nine months of intensive work to complete, and the mention of the sixth draf testifies to the amount of effort put in to get it right. All this is dismissed in two paragraphs.

The study team made detailed activity analyses of the work in operating theatres in 12 hospitals selected as representative of the various types; 65000 observations were made and are tabulated at the end of the report. The reference to "proprietorial rights" is taken out of context: thi phrase occurs in paragraph 4.9.7 and is preceded by the allusion in the study team report that at one hospital, "[operating] sessions are 'allocated' when it is known in advance that they will not be used." Read in this context I am sure the great majority of consultants would agree with more flexibility and would not feel that their status was threatened.

I trust that the confidence of surgeons and anaesthetists in the report will be restored by a fuller and balanced review in the $B M 7$-this would also restore my amicability. The repor was commissioned by ministers in response to difficulties in the running of operating theatres uncovered by visitors' reports to the Royal College of Surgeons of England. It contains importan recommendations aimed at improving the staffing, utilisation, and management of operating departments throughout the country.

P G BEVAN

Birmingham BI3 8R1)

Warden J. Accountancy for consultants. Br. Med f 1990;300:149. 20 January.

\section{Lack of knowledge has led to rift}

SIR, - We think that it is very arrogant of Scrutator to suggest that those general practitioners urging more active and hostile opposition to the new contract are necessarily ignorant of the realities of the situation. He refers to general practitioners scanning a few headlines and talking to a few colleagues.

We have been members of the Sheffield Local Medical Committee for many years and the family practitioner committee for five to 10 years and represent the local medical committee at conference. Dr T W May is secretary of Sheffield Local Medical Committee. We have discussed and dissected this contract with many of our colleagues in Sheffield, Manchester, Coventry, Belfast, Humberside, Rotherham, Barnsley, Nottingham, and Birmingham for many hours. We have had many large meetings, consulted General Medical Services Committee members, and sought legal advice. We understand fully the implications of the contract and the medicopolitical machinery, as, we believe, do most of our general practitioner colleagues. What has prevented more aggressive action against the contract proposals has not been a deep insight by members of the GMSC but a consistent majority of about 30 to 20 of GMSC members who support appeasement in direct opposition to the views expressed by experienced local medical committee members at conference and by the vast majority of general practitioners polled by the GMSC.

It is always a very mistaken view to suppose that the few can tell the majority that they know best. It is time for the GMSC to listen to its electorate.

J RUSSELI

T W MAY J POYSER

Sermitue,

Sheffield S6 $30 B$

Anonymous Lack of knowledge has led to rift $B r$ Med $\gamma$ 1990;300:218. (27 January.)

\section{Prisoners and doctors}

SIR, - Unfortunately the problems that Dr J J Geller describes in Stalinist Russia ${ }^{1}$ can be found in some African prisons today. As the medical specialist of Zomba General Hospital, Malawi between September 1986 and December 1988 looked after the prisoners admitted to the hospital's prison ward. I also visited Zomba Central Prison, the largest in Malawi, every second week. In prisoners eating little but maize meal it was common to find peripheral oedema secondary to hypoproteinaemia and vitamin deficiencies like pellagra. Five prisoners went blind from cornea damage due to vitamin A deficiency, and screening showed that more than half of all prisoners had some eye changes secondary to vitamin A deficiency.

The conditions in prison farms and in detention centres are reputedly much worse. A former colleague, Dr Mtafu, Malawi's only neurosurgeon, is presently being detained without trial in one of these.

PAUL ANTHONY REEVE

\section{Central Hospital,}

Port Vila, Vanuatu

1 Geller JI. Prisoner doctor in a Soviet labour camp 1940-1. Br Med 7 1989:299:1601-4, (23-30 December

\section{Correction}

\section{Research ethics committees}

An editorial error and a printer's error occurred in this letter by Drs Iain and Thomas Chalmers (10 February, p 395). The beginning of the third paragraph should have read: "More than 15 years ago Smithells pointed out the indefensible anomaly whereby he needed permission to give a new drug (at random) to half his patients but not to give it to all of them. The decisions of some ethical committees have promoted this ethically indefensible situation." Also, the legend to the figure should refer to antibiotics and not antibodies as printed. 